\title{
Restrictive and hypertrophic cardiomyopathies in Noonan syndrome: the overlap syndromes
}

\author{
P T Wilmshurst, D Katritsis
}

\begin{abstract}
A woman with Noonan syndrome had clinical and haemodynamic features of restrictive cardiomyopathy. There was no ventricular hypertrophy on echocardiography but myocardial biopsies showed myocyte hypertrophy without pathological disarray. This case illustrates the overlap of the cardiac phenotypes of Noonan syndrome, restrictive cardiomyopathy, and hypertrophic cardiomyopathy.
\end{abstract}

(Heart 1996;75:94-97)

Keywords: Noonan syndrome, restrictive cardiomyopathy; hypertrophic cardiomyopathy

\section{Disease phenotypes}

The relations between hypertrophic cardiomyopathy and the cardiac phenotype of Noonan syndrome and primary (non-infiltrative) restrictive cardiomyopathy are debated. The debate is complicated by absence of universally accepted criteria for the diagnosis of hypertrophic cardiomyopathy. In typical cases, phenotypes include presence of macroscopic left ventricular hypertrophy, often asymmetrical, without a haemodynamic cause; myocyte hypertrophy with a pathological degree of disarray on histological examination; and predominantly diastolic dysfunction. An outflow gradient may be present. None of these features is specific to hypertrophic cardiomyopathy and cases lacking many of the characteristics, including hypertrophy, have been labelled hypertrophic cardiomyopathy. ${ }^{12}$ Familial cases follow dominant inheritance.

Noonan syndrome is also dominantly inherited. Again, there is no generally agreed and precisely defined phenotype. Noonan syndrome is generally considered to consist of multiple congenital abnormalities. There are overlaps with other inherited diseases. Despite some similarities to Turner syndrome (such as webbed neck, short stature, and facial abnormalities) there is a normal chromosome pattern and fertility. In some families Noonan syndrome cosegregates with neurofibromatosis type $1 .{ }^{3}$ At least half of those with Noonan syndrome have cardiac abnormalities, ${ }^{45}$ which are generally similar to those associated with the cardiocutaneous syndromes (Watson and LEOPARD syndromes). Up to $20 \%$ of patients with Noonan syndrome have a cardiomyopathy with clinical features, echocardiographic and haemodynamic findings, and histopathological appearance (myocyte hypertrophy with pathological disarray) indistinguishable from the cardiac phenotype of hypertrophic cardiomyopathy. ${ }^{5}$

Restrictive cardiomyopathy also shares features with hypertrophic cardiomyopathy, notably impaired ventricular diastolic function and relatively preserved systolic function. Myocyte hypertrophy is found in both cardiomyopathies but restrictive cardiomyopathy is not associated with macroscopic hypertrophy or histological myocyte disarray. ${ }^{67}$ Myocyte disarray is a non-specific finding that is present in small amounts in the hearts of normal individuals and those with acquired hypertrophy. There is generally a high percentage of disarray in the ventricular myocardium of patients with hypertrophic cardiomyopathy, but the true percentage can only be assessed by examination of the whole heart and not from endomyocardial biopsy specimens. ${ }^{6}$

A family in which Noonan syndrome was associated with a non-hypertrophic restrictive cardiomyopathy has been described. ${ }^{8}$ Histological examination was not performed. An individual with some features of Noonan syndrome with right ventricular restriction and normal left ventricular function has been described. ${ }^{9}$ Right ventricular biopsies showed myocyte hypertrophy. Whether this respresents a form of restrictive cardiomyopathy or right ventricular dysplasia is uncertain.

There are non-cardiac similarities between these conditions. A skeletal myopathy, often subclinical, was described in association with Noonan syndrome, ${ }^{4}$ hypertrophic cardiomyopathy, ${ }^{10}$ and primary restrictive cardiomyopathy. ${ }^{611}$ In the oldest of three previously described cases of Noonan syndrome with restrictive cardiomyopathy there was a mild skeletal myopathy, which developed at the age of 45 years. $^{8}$

Thus the clinicopathological features of the cardiomyopathies and skeletal myodystrophies of Noonan syndrome, hypertrophic cardiomyopathy, and restrictive cardiomyopathy are indistinct. The overlap is illustrated by one 
study in which primary restrictive cardiomyopathy and hypertrophic cardiomyopathy are said to have been present in members of the same family.

\section{Case report}

The patient presented at age 14 years with cough and dyspnoea on exertion. There was no family history of heart disease and she had two healthy siblings. Birth and development had been normal except for short stature. Menarche was at age 11 years.

She was below the fifth centile for height $(1.52 \mathrm{~m})$ with features of Noonan syndrome consisting of a webbed neck, low-set ears, ptosis, prominent epicanthal folds, downward slanting palpebral fissures, micrognathia pectus excavatum, wide-spaced nipples, and cubitus valgus. Psychological assessment showed no intellectual deficit. She was not cyanosed and did not have clubbed digits Blood pressure was $110 / 70 \mathrm{~mm} \mathrm{Hg}$. Venous pressure was not raised. Right and left ventricular impulses were prominent. There was a fourth heart sound and a soft pulmonary systolic murmur.

The electrocardiogram showed sinus rhythm, partial right bundle branch block, left atrial hypertrophy, and $T$ wave inversion in leads V3-V6. The chest $x$ ray showed a cardiothoracic ratio of 0.44 but a large left atrium. The echocardiogram showed no valve abnormality and a mildly dilated left atrium (43 mm diameter). Left ventricular diameters (end diastolic $37 \mathrm{~mm}$, end systolic $20 \mathrm{~mm}$ ) and wall thicknesses (septum $12 \mathrm{~mm}$, posterior wall 10 $\mathrm{mm}$ ) were normal. There were no features of hypertrophic cardiomyopathy. Lung function tests were normal.

The table shows measurements made during cardiac catheterisation at age 15 . There was no evidence of an intracardiac shunt on oxyhaemoglobin saturation or dye curves. The size and contraction of the left ventricle were normal and there was trivial early systolic mitral regurgitation. The right ventricle was mildly dilated but contracted well without tricuspid regurgitation. Coronary angiograms were normal. Five endomyocardial biopsy specimens of the left ventricle were taken. Histological examination showed myocyte hypertrophy without disarray. There was no

Haemodynamic findings during cardiac catheterisation

\begin{tabular}{lr}
\hline Variable & Value \\
\hline Intracardiac pressures (mm Hg):* & \\
Mean right atrium & 5 \\
Right ventricular end-diastolic & 8 \\
Right ventricular systolic & 33 \\
Mean pulmonary artery & 20 \\
Mean left atrium & 19 \\
Left ventricular end-diastolic & 27 \\
Left ventricular systolic & 97 \\
Mean aorta & 83 \\
Cardiac index $\left(1 / \mathrm{min} / \mathrm{m}^{2}\right)$ & $2 \cdot 8$ \\
Left ventricular angiography: & \\
Left ventricular end-diastolic volume index $\left(\mathrm{ml} / \mathrm{m}^{2}\right)$ & 96 \\
Left ventricular ejection fraction $(\%)$ & 61 \\
Left ventricular mass $(\mathrm{g})$ & 101 \\
\hline
\end{tabular}

$\star^{\star}$ Reference to sternal angle. infiltration or abnormal fibrosis.

She had pregnancies at ages 17 and 21 years. Both deliveries were by emergency caesarean section because of antepartum haemorrhagge. On the first occasion Syntometrine (ergometrine/oxytocin) was given and caused pulmonary oedema. Since then she has had increasingly severe tricuspid regurgitation and dyspnoea on exertion and palpitation. Repeat echocardiograms showed that the left atrial diameter was increasing but the left ventricular dimensions remained normal.

Her third pregnancy (age 24 years) was managed with elective caesarean section. Perioperatively she had paroxysmal atrial fibrillation and a femoral artery embolus. This was treated by embolectomy and anticoagulation. Since then she has remained on warfarin and antiarrhythmic drugs. Amiodarone caused thyrotoxicosis. Currently she takes digoxin and atenolol.

Her fourth pregnancy (age 25) was terminated on medical grounds. The aborted fetus (15 weeks) appeared normal and there was no structural or histological abnormality in the heart. The same year she had a detailed neurological examination and electromyography. They excluded a skeletal myopathy. Ophthalmological examination was also normal.

Currently (aged 28) she has mild dyspnoea on exertion and atrial arrhythmias. She has moderate tricuspid regurgitation, moderate mitral regurgitation, and biatrial enlargement on the echocardiogram (left atrial diameter $56 \mathrm{~mm}$ ) but normal left ventricular dimensions and wall thicknesses.

\section{Family study}

The patient's mother (age 55 years) and her three children were examined clinically and each had an electrocardiogram and precordial echocardiogram with Doppler examination None had features of Noonan syndrome. One daughter has a small ventricular septal defect. The other two children and her mother have no evidence of heart disease. The patient's father was not available for examination and her two siblings declined the tests.

\section{Genetic factors}

Advances in molecular biology help to explain the overlap of disease phenotypes. Once single gene disorders were believed to cause discrete phenotypes. Now we know that hypertrophic cardiomyopathy is genetically heterogeneous. Linkage has been demonstrated between the hypertrophic cardiomyopathy phenotype and polymorphisms of the cardiac $\beta$ myosin heavy chain gene (chromosome 14); the cardiac troponin $\mathrm{T}$ gene (chromosome 1) and the $a$ tropomyosin gene (chromosone 15); and loci on chromosomes 11 and $7 . .^{12-14}$ In about half the cases of hypertrophic cardiomyopathy there is no linkage with any identified genetic locus. In sporadic cases, the same phenotype may be associated, possibly causally, with mutations of mitochondrial DNA. ${ }^{15}$ 
Conversely, different missense mutations of a single gene can cause variations in phenotype, depending on the precise site and nature of the mutation. ${ }^{12}{ }^{14}$ Even within familes there is considerable variation of expression of the hypertrophic cardiomyopathy genotype, with some individuals appearing to have a normal phenotype. ${ }^{16}$ Variations in expression between generations may be the result of other inherited or acquired factors interacting in individuals with the same genotype but they may also be the result of changes in the mutant gene itself. Certainly in other inherited cardiomyopathies differences between generations result from further repeat sequence expansion during mitosis or meiosis causing more florid manifestations (so called "anticipation") or normalisation of the mutant sequence ("reverse mutation"). ${ }^{17} 18$

A Noonan syndrome gene has recently been located at chromosome $12 \mathrm{q} 22$-qter ${ }^{3}$ in several families by linkage analysis. In one family, haplotype analysis showed non-linkage, indicating that for Noonan syndrome there is also genetic heterogeneity. The locus of the identified Noonan syndrome gene does not correspond with any of the known genetic loci of hypertrophic cardiomyopathy. It is not situated near the gene responsible for neurofibromatosis 1 and Watson syndrome on chromosome 17 or neurofibrosis 2 on chromosome $22 .{ }^{19}$ One patient with some characteristics of Noonan syndrome also had some features of right ventricular dysplasia, ${ }^{9}$ but a gene for right ventricular dysplasia maps to chromosome 14q23-24. ${ }^{20}$ Paradoxically, a Holt-Oram syndrome gene, which has a dissimilar phenotype, has been localised to the same region as the Noonan syndrome gene (12q22-qter). ${ }^{21}$

Primary restrictive cardiomyopathy seems to be dominantly inherited in some families, ${ }^{611}$ but the responsible gene or genes have not been identified. There are few extended pedigrees that permit linkage analysis of this rarer cardiomyopathy.

The similarities of cardiac phenotype in hypertrophic cardiomyopathy; restrictive cardiomyopathy; and Noonan, Watson, and LEOPARD syndromes are clearly not the results of different mutations of the same gene or neighbouring genes. Hypertrophic cardiomyopathy is not a single gene disorder, except within affected families. The variation in phenotype expression of the genotype has implications for detection of the presence of the disease and for counselling. There are implications for the conduct of clinical trials, including gene therapy. Incomplete penetrance also means that linkage analysis may fail to detect all the genes responsible for cardiomyopathy.

\section{Acquired factors}

The observation that similar phenotypes can be the result of abnormalities of a number of widely separate genes should initiate a search for common mechanisms by which they exert similar effects on myocyte hypertrophy and alignment.
Two of the three patients previously described with Noonan syndrome and restrictive cardiomyopathy had hyperthyroisism. ${ }^{8}$ Others have reported a $30 \%$ incidence of autoimmune thyroid autoantibodies in patients with Noonan syndrome, none of whom had overt thyroid disease. ${ }^{5}$ The patient we describe was hyperthyroid when receiving amiodarone. This may indicate predisposition to autoimmune thyroid disease, which may be familial.

Hypertrophic cardiomyopathy is also associated with hyperthyroidism, ${ }^{22}$ but the association may not be the result of genetic linkage. A cardiomyopathy with features of hypertrophic cardiomyopathy has been described in association with hypothyroidism and the cardiac abnormalities returned to normal when the patients became euthyroid. ${ }^{23}{ }^{24}$ Triiodothyronine alters the relative transcription and expression of different isoforms of myosin ${ }^{25} 26$ and affects transcription of the gene for calcium ATPase. ${ }^{27}$ These observations suggest mechanisms by which features of hypertrophic cardiomyopathy may be acquired. In young rats a condition similar to hypertrophic cardiomyopathy results from administration of triiodothyroacetic acid (an analogue of triiodothyronine with cardiac effects but little effect on total metabolic rate) to the mother during pregnancy. ${ }^{28}$ Thus acquired derangements of thyroid function can mimic hypertrophic cardiomyopathy. It also suggests that intrauterine events may be important in undertanding the aetiologies of cardiomyopathies.

When Noonan syndrome occurs in families, maternal transmission is far more common than paternal transmission. Influence of intrauterine events on expression of a genetic disease is a possible reason, but there are others. Abnormalities associated with mitochondrial DNA mutations are maternally transmitted and can be associated with a hypertrophic cardiomyopathy. ${ }^{15}$ Genomic imprinting causing differential expression of maternal and paternal DNA may result from differential methylation of maternal and paternal DNA, ${ }^{29}$ but a simpler explanation is that when genetic abnormalities result from repeat sequence amplification, the ovum will be large enough to accomodate a greater sequence amplification than the sperm, so that maternally transmitted disease will be more florid. This is the case in myotonic dystrophy, which includes a cardiomyopathy and a skeletal myodystrophy and results from increased trinucleotide repeats at chromosome $19 \mathrm{q} 13.3$.

Other mechanisms by which genetic and acquired factors can affect myocyte hypertrophy and disarray include expression of proto-oncogenes and influence of growth factors such as the local renin-angiotensin system. ${ }^{30}$

1 McKenna WJ, Stewart JT, Nihoyannopoulos P, McGinty F, Davies MJ. Hypertrophic cardiomyopathy without hypertrophy: two families with myocardial disarray in the absence of increased myocardial mass. Br Heart f 1990;63:287-90.

2 Maron BJ, Kragel AH, Roberts WC. Sudden death in hypertrophic cardiomyopathy with normal left ventricular mass. Br Heart F 1990;63:308-10. 
3 Jamieson CR, van der Burgt I, Brady AF, van Reen $\mathbf{M}$, Elsawi MM, Hol F, et al. Mapping a gene for Noonan syndrome to the long arm of chromosome 12 . Nature syndrome to the long a
Genetics $1994 ; 8: 357-60$.

4 Mendez HMM, Opitz JM. Noonan syndrome: a review. Am F Med Genet 1985;21:493-506.

5 Sharland M, Burch M, McKenna WM, Paton MA. A clinical study of Noonan syndrome. Arch Dis Child 1992;67:178-83.

6 Katritsis D, Wilmshurst PT, Wendon JA, Davies MJ, Webb-Peploe MM. Primary restrictive cardiomyopathy: clinical and pathological

7 Hirota Y, Shimizu G, Kita Y, Nakayama Y, Suwa M, Kawamura $\mathrm{K}$, et al. Spectrum of restrictive cardiomyopathy: report of the national survey in Japan. Am Heart f 1990;120:188-94.

8 Cooke RA, Chambers JB, Curry PVL. Noonan's cardiomyopathy: a non-hypertrophic variant. $\mathrm{Br}$ Heart $\mathcal{f}$ 1994;71:561-5.

9 Wilmshurst P, Da Costa P. Probable right ventricular dysplasia and patent foramen ovale presenting with cyanosis and clubbing in a patient with characteristics of Noonan and clubbing in a patient with character

10 Smith ER, Heffernan LP, Sangalang VE, Vaughan LM, Flemington CS. Voluntary muscle involvement in Flemington CS. Voluntary muscle involvement in hypertrophic cardiomyopathy. A
Ann Intern Med 1976;85:566-72.

11 Fitzpatrick AP, Shapiro LM, Rickards AF, Poole-Wilson PA. Familial restrictive cardiomyopathy with atrioventricular block and skeletal myopathy. Br Heart $f$ 1990;63:114-8

12 Watkins H, Rosenzweig A, Hwang D, Levi T, McKenna W, Seidman CE, et al. Characteristics and prognostic implications of myosin missense mutations in familial hypertrophic cardiomyopathy. $N$ Engl $f$ Med 1992;326: 1108-14.

13 Carrier L, Hengstenberg C, Beckmann JS, Guicheney P, Dufour C, Bercovici J, et al. Mapping of a novel gene for familial hypertrophic cardiomyopathy to chromosome 11. Nature Genet 1993;4:311-3.

14 Watkins H, McKenna WJ, Thierfelder L, Suk HJ, Anan R, O'Donoghue A, et al. Mutations in the genes for cardiac troponin $\mathrm{T}$ and $a$-tropomyosin in hypertrophic cardiomyopathy. $N$ Engl $\Im$ Med 1995;332:1058-64.

15 Obayashi $T$, Hattori $K$, Sugiyama $S$, Tanaka $M$, Tanaka $T$, Itoyama S, et al. Point mutations in mitochondrial DNA in patients with hypertrophic cardiomyopathy. Am Heart $\mathcal{F}$ patients with hypert

16 Fananapazir L, Epstein ND. Genotype-phenotype correlations in hypertrophic cardiomyopathy. Insights provided by comparisons of kindreds with distinct and identical $\beta$-myosin heavy chain gene mutations. Circulation 1994; 89:22-32.

17 Brunner $H G$, Jansen $G$ Nillesen $W$, Nelen $M R$ de Die CEM, Howeler CJ, et al. Brief report: reverse mutation in myotonic dystrophy. $N$ Engl $f$ Med 1993 ; mutation in

18 Shelbourne P, Davies J, Buxton J, Anvret M, Blennow E, Bonduelle $\mathrm{M}$, et al. Direct diagnosis of myotonic dystrophy with a disease-specific DNA marker. $N$ Engl Med 1993;328:471-5.

19 Flintoff WF, Bahuau M, Lyonnet S, Gilgenkratz S Lacombe D, Marcon F, et al No evidence for linkage to the type 1 or type 2 neurofibrosis loci in Noonan syndrome families. Am $\mathcal{F}$ Med Genet 1993;46:700-5.

20 Rampazzo A, Nava A, Danieli GA, Buja G, Daliento L Fasoli $\mathrm{G}$, et al. The gene for arrhythmogenic right ventricular cardiomyopathy maps to chromosome 14q23-q24. Hum Molec Genet 1994;3:959-62.

21 Terret JA, Newbury-Ecob R, Cross GS, Fenton I, Raeburn JA, Young ID, et al. Holt-Oram sydrome is a genetically heterogeneous disease with locus mapping to human chromosome 12q. Nature Genet 1994;6:401-4.

22 Bell R, Barber PV, Bray CL, Beton DC. Incidence of thyroid disease in cases of hypertropic cardiomyopathy. $\mathrm{Br} \mathrm{Heart} \mathcal{F}$ 1978;40:1306-9.

23 Altman DI, Murray J, Milner S, Dansky R, Levin SE Asymmetric septal hypertrophy and hypothyroidism in Asymmetric septal hypertrophy and

24 Santos AD, Miller RP, Mathew PK, Wallace WA Cave WT, Hinojosa L. Echocardiographic characterization of the reversible cardiomyopathy of hypothyroidism tion of the reversible cardiom

25 Dillman WH. Biochemical basis of thyroid hormone action in th heart. Am $\mathcal{F}$ Med 1990;88:626-30.

26 Morkin E. Regulation of myosin heavy chain genes in the heart. Circulation 1993;87:1451-60.

27 Rohrer DK, Hartong R, Dillman WH. Influence of thyroid hormone and retinoic acid on slow sarcoplasmic reticulum $\mathrm{Ca}^{2+}$ ATPase and myosin heavy chain $a$ gene expression in cardiac myocytes: delineation of cis-active DNA elements that confer responsiveness to thyroid hormone but not to retinoic acid. F Biol Chem 1991, 266:8638-46.

28 Pearce PC, Hawkey C, Symons C, Olsen EGJ. Role of calcium in the induction of cardiac hypertrophy and myofibrillar disarray. Experimental studies of a possible cause of hypertrophic cardiomyopathy. Br Heart $f 1985$; 54:420-7.

29 Hall JG. Genomic imprinting: review and relevance to human disease. Am f Hum Gene 1990;46:857-73.

30 Komuro I, Yazaki Y. Molecular mechanisms of cardiac hypertrophy and failure. Clin Sci 1994;87:115-6. 